\title{
DINÂMICAS LOCAIS NA IMPLEMENTAÇÃO DE POLÍTICAS PÚBLICAS: ANÁLISE DO PROGRAMẢ MINHA CASA, MINHA VIDA EM MINAS GERAIS
}

LOCAL DYNAMICS IN THE IMPLEMENTATION OF PUBLIC POLICIES: ANALYSIS OF "MINHA CASA, MINHA VIDA" PROGRAM IN MINAS GERAIS (BRAZIL)

\section{DINÁMICAS LOCALES EN LA IMPLEMENTACIÓN DE POLÍTICAS PÚBLICAS: ANÁLISIS DEL PROGRAMA “MINHA CASA, MINHA VIDA" EN MINAS GERAIS (BRASIL)}

\section{RESUMO}

A pesquisa investiga as dinâmicas locais no processo de implementação do Programa Minha Casa, Minha Vida de forma a identificar se, e como, as interações e o contexto interferem na sua execução. 0 estudo foi operacionalizado em duas etapas: análise documental, para apresentar o processo formal de implementação; e a pesquisa in loco, em municípios de Minas Gerais, atendo-se a descrever as redes de atores locais, os fatores contextuais e como isso interfere na execução do programa. Observou-se a constituição de redes entre os agentes implementadores locais e identificaram-se duas estruturas sociais particulares. A partir do conjunto de evidências, foram extraídas lições que sinalizaram para o fato de que o governo local é um coprodutor do programa; para a importância do estabelecimento de parcerias; e que os fatores contextuais importam e podem moldar a atuação dos implementadores.

PALAVRAS-CHAVE: Políticas públicas, implementação, redes, habitação, contexto local.

Vinicius de Souza Moreira ${ }^{1}$

vinicius.moreira@unifal-mg.edu.br

ORCID: 0000-0002-2398-8096

Suely de Fátima Ramos Silveira²

sramos@ufv.br

ORCID: 0000-0002-1303-7190

Fillipe Maciel Euclydes ${ }^{3}$

fillipe.euclydes@fgv.edu.br

ORCID: 0000-0001-8920-1594

${ }^{1}$ Universidade Federal de Alfenas, Instituto de Ciências Sociais Aplicadas, Varginha, MG, Brasil

2 Universidade Federal de Viçosa, Departamento de Administração e Contabilidade, Viçosa, MG, Brasil

${ }^{3}$ Fundação Getulio Vargas, Escola de Administração de Empresas de São Paulo, São Paulo, SP, Brasil

Submetido 10.07.2018. Aprovado 07.08.2018

Avaliado pelo processo de double blind review

DOI: http://dx.doi.org/10.12660/cgpc.v23n75.75955

Este artigo foi apresentado no V Encontro Brasileiro de Administração Pública, em 2018, promovido pela Sociedade Brasileira de Administração Pública. 


\section{ABSTRACT}

The research investigates the local dynamics in the process of implementation of "Minha Casa, Minha Vida" Program, in order to identify whether, and how, the interactions and context interfere with the implementation of the Program. The study was carried out in two stages: analysis of documents, to present the formal process of implementation and on-the-spot research in the municipalities of Minas Gerais, sticking to describe local actors networks, contextual factors and how they interfere with the implementation of the Program. The formation of networks among local implementers was observed and two special social structures were identified. From the set of evidences lessons were extracted that signaled to the fact that the local government is a coproducer of the program; the importance of partnerships; and that contextual factors matter and could shape the actions of implementers.

KEYWORDS: Public policy, implementation, networks, housing, local context.

\section{RESUMEN}

El estudio investiga la dinámica local en el proceso de implementación del Programa "Minha Casa, Minha Vida"(Mi casa, mi vida) con la finalidad de identificar si y cómo, la interacción y el contexto interfieren en la ejecución del programa. El estudio se llevó a cabo en dos etapas: análisis de documentos, presentar el proceso formal de la investigación de implementación y el lugar en los municipios de Minas Gerais, para cumplir con las redes de actores locales; describir factores contextuales y cómo interfiere esto con la ejecución del programa. Se observó la formación de redes entre los ejecutores locales y agentes que identificaron dos estructuras sociales particulares. Del conjunto de pruebas fueron extraídas lecciones que señalaron el hecho de que el gobierno local es un coproductor del programa; la importancia de las alianzas; y que los factores contextuales importan y podrían moldear las acciones de los ejecutores.

PALABRAS CLAVE: Políticas públicas, implementación, redes, vivienda, contexto local.

\section{INTRODUÇÃO}

O Programa Minha Casa, Minha Vida (PMCMV), desde sua criação, tornou-se a maior iniciativa do governo federal para solucionar os problemas habitacionais da sociedade brasileira. Números do período 2009-2017 reforçam a importância socioeconômica da iniciativa governamental: investimento de aproximadamente $R \$ 403$ bilhões, contratação de 5.075.148 unidades habitacionais e presença em mais de 95\% dos municípios do país (Brasil, 2018).

A relevância apresentada lança luz sobre a necessidade de investigar a forma pela qual o programa tem sido executado. Apropriando-se deste enfoque, o estudo situa-se no escopo da análise de políticas públicas (policy analysis) ao buscar interpretações sobre as causas e consequências da ação do governo na sociedade (Bardach, 2001).
Visou-se a analisar o processo político e seus subsistemas, levando-se em conta que esses "não são controlados pelos atores estatais apenas; mais que isso, eles são caracterizados pelas interações de atores públicos e privados" (Adam \& Kiesi, 2007, p. 129 - tradução nossa). A intenção, neste estudo, foi explorar a etapa de implementação, uma vez que as atividades direcionadas ao apoio à provisão habitacional ocorrem de forma descentralizada, do governo central aos municipais.

Por essas razões, em seu conjunto legislativo, o PMCMV formaliza os principais atores com responsabilidade na implementação do programa, os quais atuam em diferentes níveis. Contudo, é na esfera municipal que as principais atividades são realizadas, o que destaca o papel e a atuação dos stakeholders locais, sendo que a forma como se rela- 
cionam e os fatores contextuais podem refletir nos processos gerenciados.

Diante da conjuntura mencionada, deriva-se a seguinte inquietação: como as interações entre atores, em diferentes contextos locais, influenciam a execução do Programa Minha Casa, Minha Vida?

No intuito de responder à questão, o objetivo da pesquisa consistiu em analisar as dinâmicas locais presentes no processo de implementação do programa de forma a identificar se, e como, as interações e o contexto interferem em sua execução. E por que estudar este fenômeno social em diferentes contextos locais? Porque os problemas habitacionais, embora presentes na maioria das cidades brasileiras, acontecem de maneiras e intensidades distintas. Considerando que os agentes envolvidos no ordenamento local, as regras que regulamentam sua atuação, os recursos disponíveis compartilhados e as capacidades oscilam de contexto para contexto, observa-se que cada município compõe seu arranjo para implementação da mesma política pública (Pinto, 2016).

Além disso, dois aspectos motivaram a realização da pesquisa. O primeiro advém da expectativa para a formação de redes entre os implementadores, uma vez que há clara divisão de competências entre agentes públicos e não-públicos, definidos no aparato legal do programa, sendo que para a execução das ações os indivíduos podem se inserir em diferentes e complexos ambientes, onde participam de espaços pelos quais são afetados e os afetam (Cândido \& Abreu, 2000). O segundo aspecto remete-se aos estudos que examinaram os desdobramentos do PMCMV: as pesquisas trouxeram experiências de vá- rias partes do país, discutindo questões espaciais, econômicas, financeiras e sociais (Amore, Shimbo, \& Rufino, 2015; Cardoso, 2013; Rolnik et al., 2015; Thery, 2017), além de estudos avaliativos tanto no espaço urbano (Brasil, 2014; Moreira \& Silveira, 2017; Vicentim \& Kanashiro, 2016) quanto no rural (Andrade, Silveira, Moreira, \& Rodrigues, 2017; Bolter, Schneider, \& Haas, 2015; Silva \& Coto, 2015). Identificou-se, assim, a oportunidade de compreender as dinâmicas relacionais dos processos de implementação, principalmente no que tange à interação entre os agentes, o contexto e os reflexos na condução do programa.

É importante mencionar que o PMCMV possuiu diversas modalidades e atua nas áreas urbana e rural. O presente artigo direcionou sua atenção para a faixa urbana, na modalidade direcionada à população considerada de interesse social (com rendimento monetário familiar de até três salários mínimos/ mês). Esta modalidade é conhecida como "Programa Minha Casa, Minha Vida com recursos do Fundo de Arrendamento Residencial".

O artigo encontra-se estruturado em seis seções, a começar por esta introdução. Dedicou-se espaço para apresentar o delineamento teórico que versou a respeito da implementação de políticas públicas e das redes sociais, nas segunda e terceira seções. A seção seguinte apresenta a abordagem metodológica; em seguida, veem as discussões para os achados da pesquisa; para, ao final, traçar considerações e conclusões.

\section{A ETAPA DE IMPLEMENTAÇÃO DE POLÍ- TICAS PÚBLICAS}


No processo político, a implementação constitui-se na etapa que conecta a formulação da política à sua concretização na realidade social (Hill \& Hupe, 2009). Consiste no processo de interação entre o planejamento e a organização dos distintos recursos que auxiliarão no alcance dos fins estabelecidos (Pressman \& Wildavsky, 1973). É o momento em que a política é colocada em prática, tornando possível visualizar as diferenças entre os objetivos delineados e os resultados alcançados, principalmente em termos de obstáculos e falhas (Frey, 2000; Sabatier, 2007; Secchi, 2013).

Este estágio reúne diferentes elementos e os indivíduos são os responsáveis por dar vida aos procedimentos e imprimir a dinâmica para a condução das tarefas. A partir da atuação de implementadores, desenvolve-se diversificada rede de atores, pertencentes a diferentes níveis de governo ou a entidades não-governamentais (Mendonza, 2007; Sobrinho \& Helal, 2017). E, em meio a isso, ocorrem situações de persuasão, negociação, cooperação e conflito, pois o processo envolve a atuação política e a apropriação das atividades planejadas (Silva \& Melo, 2000; Bardach, 2001). Consequentemente, a política pública desenvolve-se, ainda mais, durante a implementação por causa dos inúmeros desafios enfrentados (Sovacool, Linnér, \& Klein, 2017), o que promove o (re)alinhamento dos objetivos e recursos conforme a viabilidade de condução das ações (Bekkers, Fenger, \& Scholten, 2017).

Considerando as características expostas, identificam-se importantes variáveis, que, em maior ou menor grau, estão presentes e influenciam a implementação. Sublinham- -se os seguintes aspectos: (a) comunicação interinstitucional e especificação de detalhes das ações, que abrangem auxílios técnicos e informacionais, controlados por remuneração, coerção ou normas; (b) características das agências, isto é, tamanho e competência da equipe executora; formas de controle, autonomia, graus de abertura de comunicação; e (c) o contexto, cujas circunstâncias políticas, econômicas e sociais são reflexos da disponibilidade de recursos, das condições socioeconômicas, da opinião pública, e do posicionamento das elites e de grupos privados (Jann \& Wegrich, 2007; Viana, 1996).

Cabe aqui reforçar que o contexto é um importante componente da análise, pois suas variáveis e imperativos "limitam, constrangem e influenciam a implementação das políticas, como os processos de barganha, as relações entre os atores" (Sobrinho \& Helal, 2017:122).

As variáveis anteriormente descritas permitem inferir que a implementação é um processo complexo e dinâmico, no qual aspectos formais, comportamentais e do contexto influenciam a condução das intervenções públicas. Devido a isso, entende-se que tal processo envolva duas dimensões (Lima \& D'ascenzi, 2013): a normativa, representada pelos marcos regulatórios, vista como a execução de atividades para o cumprimento das metas traçadas na formulação; e a comportamental, que concentra as análises na atuação dos agentes.

Portanto, o estudo do PMCMV fundamentou-se nessas duas dimensões para consubstanciar as respostas sobre a problemática delineada. Além disso, para entender a atuação dos implementadores do programa, 
associaram-se as premissas da policy network - redes de políticas públicas -, haja vista o interesse de estudar as relações que mobilizam e incorporam recursos dispersos, de modo que a ação coletiva se organize na direção da solução de um problema comum (Börzel, 1998). De acordo com Capella e Brasil (2015), a perspectiva da policy network, na medida em que compreende os atores governamentais também como atores sociais, permite desenvolver explicações sobre como o relacionamento entre o Estado e os diferentes grupos influenciam o processo político.

\section{REDES SOCIAIS NO ÂMBITO DAS POLÍ- TICAS PÚBLICAS}

A abordagem de rede não é recente e possui raízes sociológicas e antropológicas (Tichy, Tushman, \& Fombrun, 1979). A intensificação dos debates no plano teórico e técnico-operacional imprimiu status de aceitação na comunidade científica, proporcionando a disseminação de estudos nas mais diversas áreas, sendo a administração pública um campo propício para ela (Howlett \& Maragna, 2006).

O conceito de redes aplicado às ciências sociais enfatiza a interação entre indivíduos, dadas as relações estabelecidas, fornecendo meios para entender os fenômenos da sociedade (Fontes, Leal, \& Melo, 1995). Neste sentido, a conceituação de redes sociais é amplamente discutida por diversos autores (Adam \& Kriesi, 2007; Borgatti \& Foster, 2003; Marques, 1999; Nelson, 1984; Steiner, 2006; Wasserman \& Faust, 2009) e, embora existam nuances nas assertivas, há três elementos comuns: atores, relações e compartilhamento. Destarte, entendeu-se a rede social como sendo a estrutura formada por emaranhado de atores que estabelecem conexões entre si (de diferentes direções e naturezas) e, a partir dos laços, compartiIham e interagem em torno das fronteiras invisíveis resultantes dos relacionamentos.

A incorporação das redes no âmbito das políticas públicas descortina as redes de políticas públicas, nas quais os elementos comuns à rede social inserem-se em estruturas que movimentam recursos públicos, políticos e a tomada de decisão, sendo que a produção dos bens ou serviços são distribuídos entre atores públicos e não-públicos (Agranoff \& Mcguire, 1999; Schneider, 2005). Trata-se de um modelo que avança na compreensão das diversas formas de articulação entre Estado e sociedade civil, em que, idealmente, as redes de política pública são vistas como estruturas nas quais o poder é compartilhado por diferentes organizações, não apresentando assimetrias em suas relações (Rhodes, 1997).

Adam e Kriese (2007) distinguiram três abordagens para o uso do conceito de policy network: aquela que designa novas estruturas de governança (hierarquia vs. horizontalização); aplicação em diferentes situações empíricas em que há a interação entre atores públicos e privados, em específicos subsistemas políticos; e a abordagem quantitativa (análise de redes sociais), cujo resultado são sociogramas e a mensuração de índices (centralidade, densidade, conexões e etc.).

Esta pesquisa, em particular, aplicou o conceito de policy network para compreender as interações entre os implementadores locais do programa "Minha Casa, Minha Vida", 
na busca por reconhecer "a importância de uma variada gama de atores no processo de políticas públicas (policy process) com capacidade para influenciar seus resultados (policy outcomes)" (Ferrari \& Nunes, 2008, p. 3).

De modo geral, elementos como diversidade de atores, multiplicidade de objetivos, distribuição de recursos e formas de interação têm adquirido cada vez mais relevância nos estudos sobre políticas públicas (Sabatier, 2007). No Brasil, destacam-se as pesquisas de Marques E.C. (1999, 2000, 2006), que investigaram as relações entre atores estatais e não-estatais na elaboração/implementação de políticas públicas urbanas, tendo como pano de fundo as experiências em São Paulo e no Rio de Janeiro. A principal ideia discutida nos trabalhos de Marques é a permeabilidade do Estado que "é produzida a partir de uma teia de relações e cumplicidades, construída ao longo da vida dos indivíduos, incorporando diferentes tipos de elo" (2006, p. 49). E é, justamente, em torno da estruturação das redes que "conforma o que denominamos de permeabilidade, tornando difusas as fronteiras entre público e privado" (2006, p. 49).

Ressaltam-se, adicionalmente, outros estudos (tanto nacionais quanto internacionais) que analisaram específicas políticas públicas em diferentes níveis governamentais e contextos, investigando estruturas e dinâmicas estabelecidas pelos agentes implementadores e suas conexões.

No campo da saúde, citam-se as pesquisas de Holden e Lin (2012), que utilizaram a análise de rede como abordagem analítica para explicar como as características estruturais podem influenciar os atores que participam de diferentes fases funcionais do policy cycle. Para ilustrar tal fenômeno, foi estudada a Política Nacional de Saúde Masculina da Austrália. E o estudo de Lotta e Pavez (2010), que abordaram a implementação das políticas públicas no nível local, a partir do estudo da mediação estrutural e da dinâmica estabelecida pelos agentes implementadores entre a população e o poder público. O público-alvo da investigação foram os agentes comunitários de saúde do Programa Saúde da Família que atuavam nos municípios de Sobral (CE), Taboão da Serra (SP) e São Paulo (SP).

Na área das políticas urbanas, além dos trabalhos de Marques (1999, 2000, 2006), há as pesquisas de Pinto (2016), que examinou dados de estudos experimentais cujo foco foi observar as interações sociais e seus efeitos nos resultados de políticas norte-americanas relacionadas à habitação e educação; e Ysa, Sierra e Esteve (2014), que enfatizaram a gestão das redes formadas no entorno de projetos de revitalização urbana realizados na Catalunha (Espanha), com destaque para elementos como confiança, complexidade e liderança.

E, também, apresenta-se a pesquisa de Sobrinho e Helal (2017) que focalizou a análise da implementação do Programa de Artesanato Paraibano aglutinando dois modelos teóricos: o primeiro, construído com base em experiências internacionais e destinado à compreensão da dinâmica político-institucional; e o outro, que considera as especificidades da dinâmica política nacional, com ênfase na interação entre os atores envolvidos na implementação e as circunstâncias desse processo. 
Uma das principais conclusões deste conjunto de pesquisas é que o desempenho/ resultado das políticas e dos programas é influenciado pelo comportamento e interação das partes interessadas que participam direta ou indiretamente das intervenções. Assim, a análise dos stakeholders e das redes que se constituem a partir do compartilhamento de recursos e relações podem auxiliar em: determinar os tipos de atores envolvidos e dimensionar a intensidade das ligações, os motivos e as direções; identificar os tipos de colaborações necessárias para executar os projetos; além de entender o papel que a rede desempenha na realização de atividades (Brugha \& Varvasovsky, 2000; Schneider, 2005; Sobrinho \& Helal, 2017).

Sendo assim, com base na compreensão da relação estabelecida entre implementação e redes sociais, a expectativa teórica foi transformada em modelo analítico (Figura 1).

Figura 1. Perspectiva analítica da implementação do PMCMV

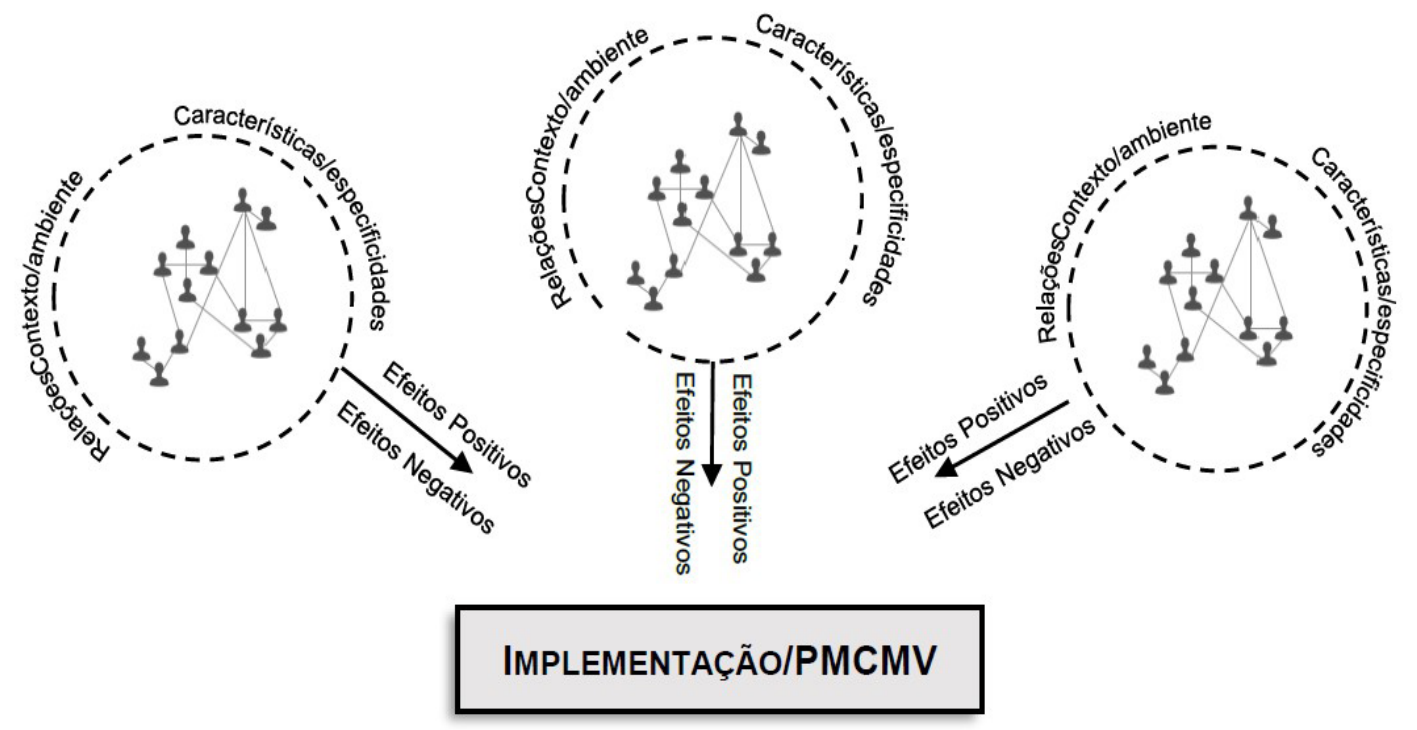

A execução de um programa envolve processos de persuasão, negociação, cooperação e conflito circunscritos num contexto/ ambiente particular. Consequentemente, na medida em que as interações e o compartilhamento de recursos ocorrem, formam-se diferentes tipos de redes, as quais podem ter efeitos positivos e/ou negativos na implantação da política pública estudada.

\section{ABORDAGEM METODOLÓGICA}

A pesquisa, de caráter qualitativo, foi operacionalizada em duas etapas: análise dos normativos sobre o PMCMV; e a pesquisa empírica in loco, atendo-se a descrever as redes de atores locais, os fatores contextuais e como estes interferem na execução do programa. O horizonte temporal abrangeu 0 período de 2009 a 2014, que representa as duas fases iniciadas e concluídas: PMCMV-I (2009-2010) e PMCMV-II (2011-2014).

Para estudar o corpo legislativo do progra- 
ma, fez-se uso da análise documental das principais leis e portarias que o regulamentam (Quadro 1). A intenção foi identificar os elementos formais que caracterizam a implementação do PMCMV.

Quadro 1: Legislação do PMCMV analisada

\begin{tabular}{|c|c|}
\hline Documento & Descricão \\
\hline & Dispôe sobre os parâmetros de priorizaçâo e o processo de seleção dos beneficiários do \\
\hline 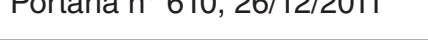 & \\
\hline Portaria $n^{\circ} 168 \quad 12 / 04 / 2013$ & Dispõe sobre as diretrizes gerais para aquisição e alienação de imóveis com recursos \\
\hline & [...] FAR, no âmbito do PNHU, integrante do PMCMV. \\
\hline & Termo que firma a parceria entre a União e o município que participa do programa. Traz \\
\hline Termo de adesão ao PMCMV & as principais atribuições e os compromissos com que ambas as partes se comprometem \\
\hline & ao firmar o acordo. \\
\hline Especificações mínimas das & Especificaçoes mínimas para contratação com valor máximo de aquisição da unidade de \\
\hline U. $\mathrm{H}^{1}$ & acordo com a Portaria $n^{\circ} 168,12 / 04 / 2013$. \\
\hline
\end{tabular}

Nota: ${ }^{1}$ Unidades Habitacionais.

De posse das informações normativas, procedeu-se à pesquisa em campo para analisar o aspecto comportamental da implementação. A investigação focou o Estado de Minas Gerais, que possui o segundo maior déficit habitacional, sendo que havia, em 2014, 529 unidades nesta condição (Fundação João Pinheiro [FJP], 2016); e foi o quarto Estado brasileiro que mais contratou moradias pelo PMCMV no período 2009-2014.

A escolha das localidades estudadas pautou-se em três processos: de início foi realizado o agrupamento dos municípios contemplados pelo programa (67 em todo o Estado) conforme características socioeco- nômicas e demográficas (fez-se uso da análise de cluster), o que proporcionou quatro grupos; em seguida, em cada agrupamento, os municípios foram ranqueados em função do número de moradias contratadas (do maior para o menor); e por fim foram selecionados, em cada agrupamento, dois municípios com maior número de moradias contratadas, tendo em vista a disponibilidade e o assentimento voluntário de participação na pesquisa. Este processo, que gerou distintos perfis municipais, resultou em oito municípios, os quais foram investigados: Alfenas; Almenara; Betim; Ituiutaba; Janaúba; Juiz de Fora; Montes Claros e Uberlândia (Figura 2). 
Figura 2. Municípios selecionados para estudo in loco

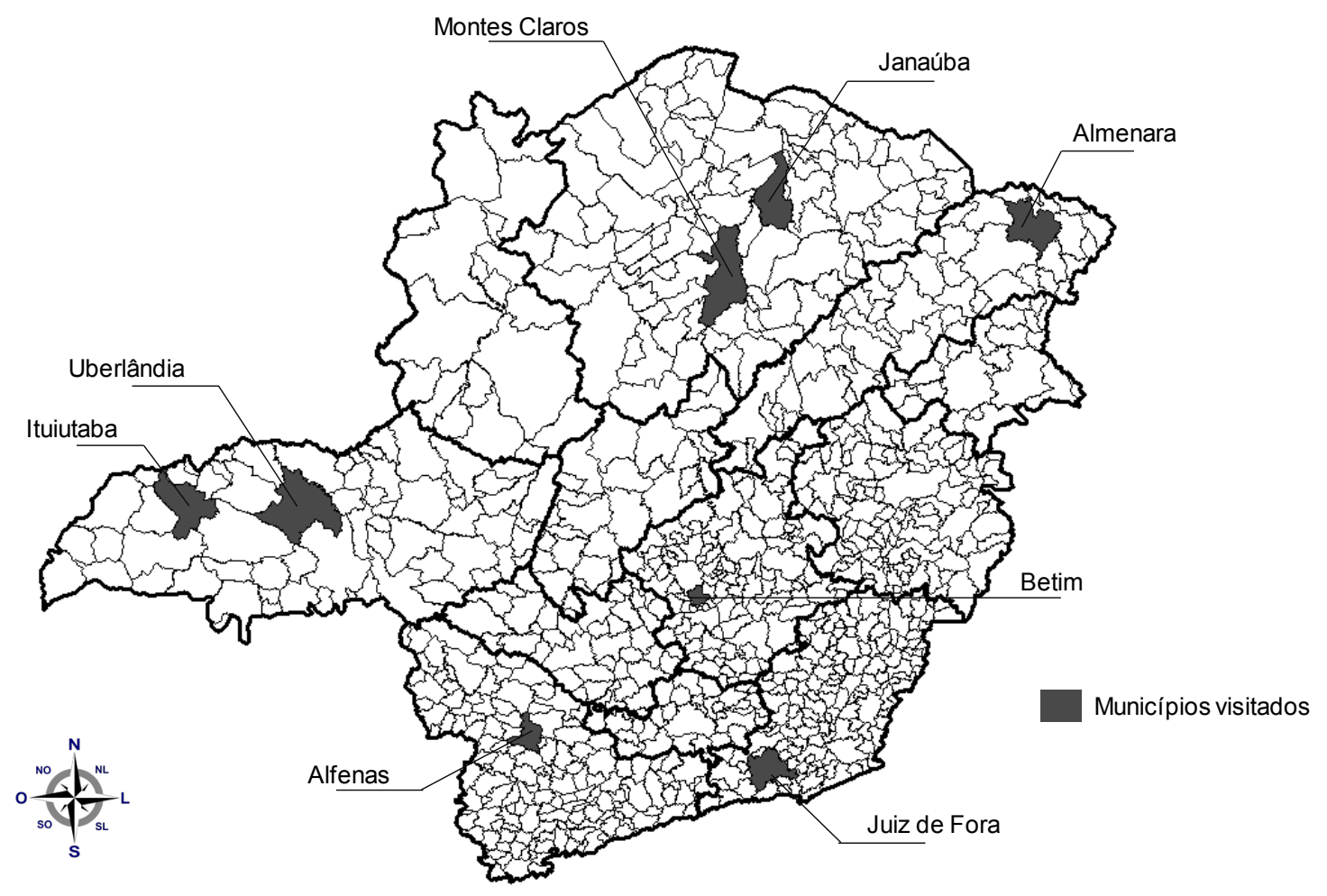

Fonte: Baseado no software TabWin.

Em cada localidade, o público-alvo abrangeu os gestores públicos locais que mais se envolveram na gestão ou no acompanhamento das atividades de implementação do programa. Os sujeitos foram abordados a partir de entrevistas com roteiros semiestruturados. No total, foram entrevistados 24 gestores, com média de idade de 43 anos (25 o mínimo e 63 o máximo). A maioria foi do sexo feminino $(60 \%)$. Todos possuíam ensino superior, principalmente nas áreas de serviço social, engenharia civil e administração.

A apreciação e interpretação do conjunto de informações pautaram-se na análise de conteúdo conforme indicações de Bardin (2009). As categorias analíticas, estabelecidas a priori, estão dispostas no Quadro 2. 
Quadro 2. Categorias analíticas

\begin{tabular}{|c|c|c|}
\hline Categoria & Definição/Descrição & Principais Bases Teóricas \\
\hline $\begin{array}{l}\text { Processo formal de } \\
\text { implementação }\end{array}$ & $\begin{array}{l}\text { Especificação dos detalhes das açôes ê dos atores } \\
\text { responsáveis. }\end{array}$ & \\
\hline $\begin{array}{l}\text { Rede de } \\
\text { implementadores }\end{array}$ & $\begin{array}{l}\text { Características das agências: tamanho e competência } \\
\text { das equipes. Detalhamento dos principais envolvidos, } \\
\text { interdependentes oy não, de um único ou múltiplos setores. }\end{array}$ & $\begin{array}{l}\text { Viana (1996); Brugha e } \\
\text { Varvasovsky (2000); Silva }\end{array}$ \\
\hline Interação & $\begin{array}{l}\text { Caracterização das interaçoes durante a execução das } \\
\text { atividades, compreendendo os motivos, e se partem de } \\
\text { interesses comuns ou não. }\end{array}$ & $\begin{array}{l}\text { e Melo (2000); Schneider } \\
\text { (2005); Jann e Wegrich } \\
\text { (2007); Lima e D’ascenzi }\end{array}$ \\
\hline Fatores contextuais & $\begin{array}{l}\text { Círcunstâncias políticas, econômicas e sociais que refletem a } \\
\text { disponibilidade de recursos, as condições socioeconômicas, a } \\
\text { opinião pública, bem como o posicionamento das elites e de } \\
\text { grupos privados. }\end{array}$ & $\begin{array}{l}\text { (2013); Sobrinho e Helal } \\
\text { (2017). }\end{array}$ \\
\hline
\end{tabular}

A grade interpretativa derivou-se da interseção entre implementação e redes de políticas públicas. Para o tratamento das informações coletadas, foram utilizados os softwares $\mathrm{Ne}$ tDraw e UCINET, os quais possibilitam o processamento e a representação gráfica da rede. Os elementos da investigação resultaram em mapeamentos qualitativos do processo de interação, baseados nas indicações dos entrevistados, cuja materialização ocorreu por meio de ilustrações explicadas na Figura 3.

Figura 3. Representação dos elementos das redes

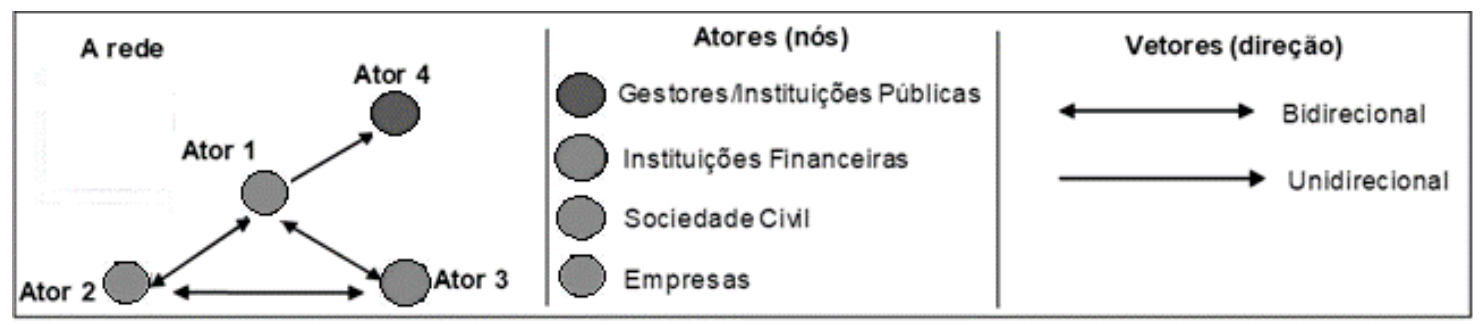

\section{RESULTADOS E DISCUSSÃO}

O processo formal de implementação do Programa Minha Casa, Minha Vida

Ao examinar o marco regulatório, que direcionou a execução do PMCMV no período 2009-2014, desvela-se o processo formal de implementação do programa (Lima \&
D’ascenzi, 2013; Sobrinho \& Helal, 2017); e dele apreendem-se as principais atividades e os respectivos agentes responsáveis por executá-las e acompanhá-las (Jann \& Wegrich, 2007; Mendonza, 2007; Viana, 1996). A totalidade de ações foi classificada de acordo com suas especificidades, em quatro grandes grupos (Quadro 3). 
Quadro 3. Conjunto de atividades e agentes responsáveis

\begin{tabular}{|c|c|c|c|}
\hline Grupo de Atividade & \multicolumn{3}{|c|}{ Responsáveis } \\
\hline $\begin{array}{l}\text { 1. Preparar a proposta de empreendimento } \\
\text { 2. Executar a proposta de empreendimento }\end{array}$ & Empresa construtora & Governo municipal; & Ministério das \\
\hline 3. Executar o trabalho social & Governo municipal & Instituicão financeira & Cidades \\
\hline
\end{tabular}

Fonte: Resultados da pesquisa.

A partir do delineamento formal do PMCMV, a proposta de empreendimento, que deve conter todas as especificações do projeto habitacional, é preparada pela empresa construtora e enviada à instituição financeira para análise e ao governo municipal para apreciação geral. Aprovada, a proposta torna-se apta a ser executada, sendo responsabilidade da construtora a finalização do empreendimento. Cabe à instituição financeira o monitoramento das obras e a remuneração da empresa, que deve respeitar o cronograma físico-financeiro estipulado. $O$ governo local pode promover ações facilitadoras para colaborar com o cumprimento dos prazos das obras. $O$ cadastramento, a seleção dos beneficiários e a execução do trabalho social são competências exclusivamente municipais, julgadas e acompanhadas pela instituição financeira.
O processo empírico de implementação do Programa Minha Casa, Minha Vida em munic ípios de Minas Gerais

Com base no delineamento formal, o estudo in loco dedicou-se ao viés comportamental da implementação. Esta orientação permitiu compreender como ocorria o referido processo na realidade social. Assim, no primeiro momento constitui-se a rede de implementadores para, adiante, analisar as interações e os fatores próprios dos contextos e os efeitos na execução do Programa.

\section{A rede de implementadores do PMCMV}

A pesquisa empírica teve o intuito de identificar se os implementadores do PMCMV constituíam uma rede. $\mathrm{E}$, a partir das análises sobre as experiências e os contextos locais, foi possível derivar duas estruturas sociais específicas, ilustradas na Figura 4. 
Vinicius de Souza Moreira - Suely de Fátima Ramos Silveira - Fillipe Maciel Euclydes

Figura 4. Redes sociais identificadas

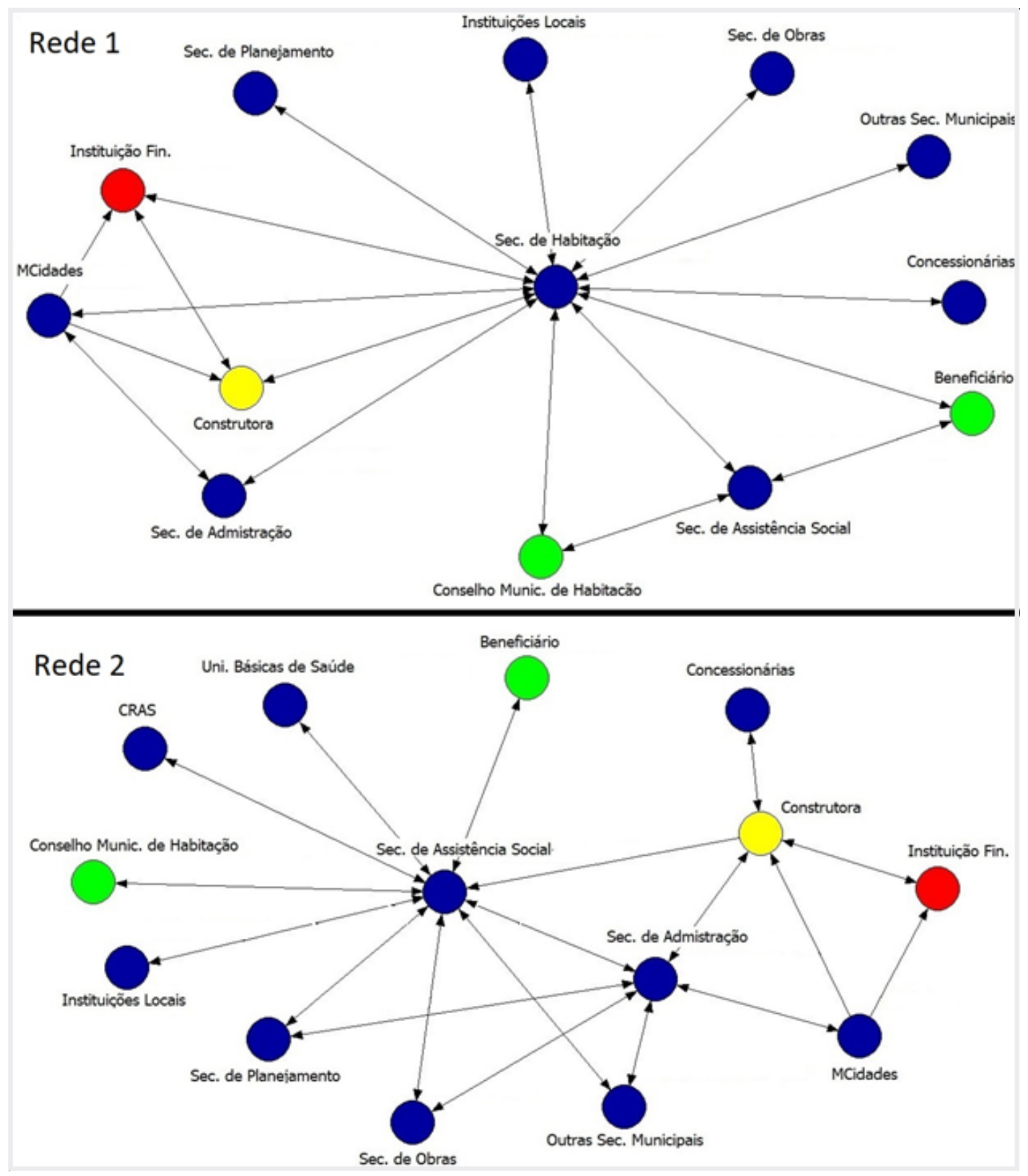


A principal característica diferenciadora das redes foi um atributo particular do contexto político-institucional da administração pública local: a existência (ou não) de uma secretaria municipal direcionada à habitação. Em parte das localidades havia este órgão (Rede 1) que, geralmente, tinha no quadro de servidores públicos profissionais com formações específicas em arquitetura, administração, geografia, engenharia civil e assistência social. Por outro lado, os municípios que não contavam com a referida secretaria (Rede 2) dispunham de um departamento habitacional vinculado às secretarias municipais de assistência social, gerenciado majoritariamente por assistentes sociais e administradores.

Considerou-se este atributo do contexto local como sendo o ponto de inflexão das estruturas, pois na Rede 1 havia uma equipe multidisciplinar de gestores, ou seja, com diversificadas competências para atuação ante as necessidades do programa, o que vai ao encontro da proposição de Abiko (1995, p. 12), que preconizou que a construção de moradias deva ser "resultado de um processo complexo de produção com determinantes políticos, sociais, econômicos, jurídicos, ecológicos e tecnológicos".

Cabe ressaltar, ainda, as características socioeconômicas gerais dos municípios que compuseram cada rede. Na Rede 1, em média, a renda per capita é de $R \$ 840,88$; a população é de 465.066 pessoas; a taxa de urbanização, 97,63\%; e foram construídas 3.110 unidades habitacionais no âmbito do programa. Para a Rede 2, os valores médios foram: renda per capita de $\mathrm{R} \$ 624,04$; população de 69.131 pessoas; taxa de urbanização, 90,53\%; e 1.181 unidades habitacio- nais construídas no âmbito PMCMV (dados para o período 2009-2014).

Mas quais eram, de fato, os atores em nível local? Em ambas as redes identificou-se a atuação dos agentes especificados nos normativos (Quadro 3). Todavia, o número de atores expandiu e diversificou em razão das particularidades que os municípios necessitavam para implementar o PMCMV. Emergiram outras instituições, tais como: Polícia Militar; Sebrae; concessionárias de serviços públicos (saneamento básico, coleta de lixo e energia elétrica); e os conselhos municipais de habitação. Ademais, a própria administração pública municipal dispunha de outras secretarias para realizar e/ou acompanhar atividades, como as de obras, planejamento, meio ambiente; administração ou governo; e ainda as de educação/cultura e saúde.

Nota-se que a implementação do caso particular do PMCMV, em Minas Gerais, compartilha de um atributo peculiar às redes de políticas públicas, isto é, o envolvimento de atores e agentes não-públicos de outras áreas sociais - caráter intergovernamental e interorganizacional (Brugha \& Varvasovsky, 2000; Schneider, 2005); além de serem interdependentes e de múltiplos setores, propriedades ressaltadas nas redes de políticas públicas analisadas por Holden e Lin (2012) (caso da Austrália e setor da saúde), Ysa et al. (2014) (contexto da Espanha e setor urbano) e Sobrinho e Helal (2017) (pesquisa nacional sobre o Programa de Artesanato da Paraíba).

Redes, interações e fatores contextuais na implementação do PMCMV 
Uma vez observada a constituição das redes e definidos os partícipes, buscou-se interpretar como a interação entre os agentes e os fatores contextuais influenciaram a implementação do programa. Para esta análise, retomou-se cada um dos grupos de atividades descritos no Quadro 3, sendo que o comportamento e os resultados identificados são descritos a seguir.

\section{-- Preparar a proposta de empreendimento}

Esta atividade é de responsabilidade da empresa construtora, e a espinha dorsal da etapa é a escolha do terreno. Decidir sobre a área que abrigará os conjuntos habitacionais determina os rumos da execução do projeto. Para esta deliberação, a legislação do PMCMV determina que o local para construção dos empreendimentos deva contemplar a existência ou viabilidade de infraestrutura, equipamentos comunitários e serviços (creches ou escolas de ensino fundamental; Unidades Básicas de Saúde; Centros de Referência de Assistência Social; áreas de lazer; linhas regulares de transporte público; comércio e serviços locais).

Em ambas as redes, os terrenos, na maioria dos casos, eram da própria construtora ou negociados diretamente por ela com os proprietários. Estas transações eram pautadas pelo caráter contratual e econômico do negócio, isto é, o interesse do proprietário do imóvel era a valorização de seu bem, e, do lado do adquirente, a finalidade tendia a ser a aquisição a menor custo. Reconheceu-se que era o valor do imóvel (de interesse da construtora), a variável definidora para a escolha do terreno, sobressaindo-se em relação aos critérios do Programa (de interesse da gestão pública). Essas áreas, con- sequentemente, tendiam a ser longínquas e deslocadas de regiões já dotadas de infraestrutura urbana. A ocorrência de edificações inseridas nestes locais gerou uma série de consequências para administração pública municipal, uma vez que foi necessário prover equipamentos públicos ou realocar demandas para outras regiões com baixas condições de absorver novas solicitações.

Identificou-se, ainda, a presença de grupos de interesses do setor privado, relacionados à indústria da construção civil e ao mercado imobiliário, com majoritária influência nas resoluções acerca da proposta de projeto. Em Marques (1999; 2006), a condução das políticas públicas de infraestrutura urbana era influenciada por grupos privados que destinavam ações à produção do espaço urbano. A habitação, por sua vez, compreende um dos eixos de atuação da política urbana e, para o caso do PMCMV em Minas Gerais, observou-se a replicação deste sistema produtivo, reforçando o predomínio de interesses privados ante ao interesse público.

Todavia, nos contextos em que existia a secretaria municipal de habitação (Rede 1), este órgão, a partir de sua expertise, sinalizava posturas para dirimir o predomínio das empresas nas proposições. Buscava-se barganhar melhores localizações e benfeitorias aos residenciais (como a construção de áreas de lazer/convivência e praças, por exemplo). Na Rede 2, por outro lado, esse poder de negociação era mais limitado, sendo que a ausência da secretaria de habitação transpareceu aspecto difuso, de baixa coordenação e, por isso, menor capacidade de articulação com as empresas: as questões relacionadas à implementação do Programa dirigiam-se quase que exclusivamente aos 
aspectos assistenciais em detrimento dos construtivos, que transitavam por outras secretarias (obras, planejamento) sem a apropriação, de fato, pelo governo local.

Interessante mencionar que os municípios da Rede 2, de condições socioeconômicas e porte menores, encontravam-se em posição de disputa política por recursos: se não fosse aceita a proposta da construtora, esta poderia migrar o projeto para outro município semelhante, deixando os primeiros sem a execução do PMCMV. Aos municípios da Rede 1, não incorriam essas assimetrias, pois devido ao maior nível de desenvolvimento, tamanho e o elevado déficit habitacional, havia maior cota para construção de moradias, mostrando-se terrenos férteis para empresas deste ramo.

É válido assinalar que a atuação da secretaria municipal de habitação (na Rede 1) e da empresa construtora (na Rede 2), as colocam em evidência devido aos efeitos de suas posições no seu entorno relacional (Lotta \& Pavez, 2010). No caso das secretarias na Rede 1 , sua posição intermediadora auxiliava em deliberações que melhor compactuavam com as indicações do Programa, diminuindo os efeitos de decisão hegemônica das construtoras; por outro lado, na situação de posicionamento mais influente das empresas na Rede 2, seu papel na estrutura sobrepõe-se aos demais, deixando pouco espaço para compartilhamento de interesses na tomada de decisão.

-- Executar a proposta de empreendimento

Assim como na etapa anterior, a responsabilidade para a execução da proposta de empreendimento é da construtora. A orga- nização deve seguir as recomendações sob pena de sanções da instituição financeira que monitora 0 andamento das obras. $O$ governo local (em ambas as redes), por intermédio de suas secretarias, embora não influencie nos procedimentos de edificação em si, tinha o papel fundamental na intermediação de processos de licenciamento ambiental, parcelamento do solo; criação de linhas de transporte público; e no planejamento e execução de iniciativas, haja vista as demandas sociais por serviços de saúde, educação, lazer e cultura que eram geradas pelas famílias realocadas em um novo espaço do perímetro urbano.

As relações, no decorrer desta atividade, eram predominantemente de caráter contratual e baseadas nos princípios da economicidade e eficiência. Atributos da gênese do programa que delega a construção das moradias às empresas privadas e estipula, de um lado, especificações mínimas e, de outro, o valor máximo de custo da unidade: a soma destes fatores traduz-se em unidades com os padrões mínimos ao menor custo, mesmo que possa comprometer a qualidade dos produtos entregues.

Os desdobramentos negativos dessas ações são alvos de discussões na literatura nacional e as evidências desta pesquisa coadunam com as realidades de outros Estados brasileiros. A esse respeito, cabe destacar que os resultados deste estudo, bem como outras pesquisas, trazem reflexões importantes relacionadas: à estrutura socioespacial e à produção habitacional (massificada), como em Amore et al. (2015) e Nascimento (2017), marcante na maioria dos conjuntos habitacionais erguidos pelo PMCMV em todo o país; à ampliação do 
mercado da moradia em espaços periféricos (localização dos empreendimentos), o que dificulta 0 acesso à cidade e acentua a segregação espacial, a exemplo de investigações realizadas para municípios de Minas Gerais (Moreira \& Silveira, 2017); do Rio Grande do Sul (Vasconcellos, 2015); e do Espírito Santo (Magris, 2013); bem como nas regiões metropolitanas de Goiânia-GO (Moysés, Cunha, Borges, \& Maia, 2013), Belém-PA (Lima, Ponte, Rodrigues, Neto, \& Melo, 2013), Natal-RN (Silva, 2014) e São Paulo-SP (Rolnik et al., 2015); e quanto ao embate entre o interesse social e o interesse imobiliário, apresentado por Soares, Carvalho, Filho, e Barbosa (2013), no caso de Uberaba-MG.

Em complemento a tais considerações, a análise empírica desta pesquisa indicou outros atributos de destaque que, de acordo com as dinâmicas entre contexto, implementação e redes, podem explicar os desdobramentos da execução do PMCMV. Foi notório que, quanto maior o envolvimento dos gestores públicos locais, mais coordenadas tendiam a ser as ações e o provimento habitacional não ficava à mercê do mercado. $\mathrm{E}$ no contextos faziam-se presentes um corpo técnico especializado, uma secretaria coordenadora do programa e melhores atributos socioeconômicos (Rede 1), nos quais as deliberações se mostraram mais articuladas, reduzindo o protagonismo da empresa construtora.

A administração pública local, embora não executora direta do programa, pode (e deve) envolver-se nos processos de construção das casas e, por isso, pode intermediá-los e (tentar) garantir o adequado cumprimento das obras/atividades contratadas. Identifi- cou-se, na Rede 1, que havia maior nível de apropriação por parte de gestores públicos. Além de agilizar os processos públicos, os atores estendiam a participação de modo a acompanhar as etapas de construção e estabelecer parcerias para reduzir efeitos indesejados, como a edificação de empreendimentos em lugares de urbanização precária.

\section{-- Cadastrar e selecionar os beneficiários}

As atividades deste bloco consistem na realização do cadastramento e seleção das famílias para que as selecionadas se tornem aptas ao recebimento do benefício. Sob este aspecto, ambas as estruturas demonstraram similaridade na execução (modus operandi) das atividades, em virtude de estas ações serem responsabilidade das secretarias municipais de assistência social e acompanhadas pela instituição financeira.

É neste momento que surge outro ator no cenário local: o Conselho Municipal de Habitação (CHM). Poder-se-ia imaginar que este espaço auxiliasse no controle e promovesse a participação social ante as ações do programa. Porém, o CMH ficava restrito à escoIha dos critérios locais para seleção dos beneficiários. E, em determinados municípios, após a finalização das obras, o conselho era extinto. Casos semelhantes também foram apurados em outros municípios de Minas Gerais, conforme constataram Silveira, Moreira, Silva, e Andrade (2018). Estas evidências, assim como a própria gênese top down do programa, denotam o pouco espaço para envolvimento da sociedade, reduzindo o diálogo e fazendo com que a rede desconsidere um ator-chave nos processos decisórios que visem ao bem-estar comunitário (Schneider, 2005), o que fragiliza a relação entre a socie- 
dade civil e o Estado.

Detectou-se um traço peculiar da Rede 2 diante de suas limitações: a busca por parceiros dentro da própria hierarquia administrativa para que as atividades pudessem ocorrer. Utilizavam-se da capilaridade da estrutura, por meio dos profissionais do Centro de Referência e Assistência Social e de agentes comunitários das Unidades Básicas de Saúde para comunicar-se diretamente com famílias público-alvo do PMCMV. Isto significa a existência de agentes capazes de estabelecer conexões tanto verticais, decorrentes dos contatos com o público-alvo, quanto horizontais, uma vez que geram mobilização, trocas de informação internas e articulação com agentes públicos de áreas correlatas, evidência também observada por Lotta e Pavez (2010), no âmbito da atuação de agentes comunitários de saúde do Programa Saúde da Família em municípios dos Estados de São Paulo e Ceará.

Além disso, os agentes da Rede 2 recorriam a outras secretarias para a resolução de pendências documentais e para a solicitação de áreas para realização do cadastro das famílias (pois na época de divulgação do programa os espaços existentes não teriam condições de comportar o volume de interessados), reforçando a importância da integração entre os atores intragovernamentais (Schneider, 2005).

\section{-- Executar o trabalho social}

O último conjunto de atividades compreende a execução do trabalho social, cuja finalidade é promover a socialização das famílias. Trata-se de um conjunto de ações socioeducativas para fomentar a organização comu- nitária; educação ambiental e patrimonial; planejamento e gestão do orçamento familiar; e geração de trabalho e renda. A última etapa da implementação do PMCMV, assim como a anterior, é de responsabilidade do governo municipal (desenvolvida e executada pelas secretarias de assistência social) sendo monitorada pela instituição financeira.

Perante esta atividade, as experiências locais foram diversificadas. Embora em todos os municípios da Rede 1 esta etapa tenha sido executada, o trabalho social não foi realizado em todos os empreendimentos, sendo exigência do PMCMV. A principal alegação referia-se ao processo moroso de confecção e aprovação do projeto, uma vez que deve ser elaborado pelo governo local, apreciado pela instituição financeira e seguir para aprovação e liberação do recurso. Esses descompassos decorrentes da morosidade processo podem diminuir a confiança do público na intervenção (Silva, 2018; Ysa et al., 2014) e desmotivar a participação em atividades que requerem o envolvimento de beneficiários, o que é o caso do trabalho social.

Por outro lado, o resultado mais crítico ocorreu nos municípios da Rede 2, que apresentaram situações em que o trabalho social não foi realizado em nenhum empreendimento construído. Outros resultados assemelham-se aos achados aqui comentados.

Numa pesquisa nacional, realizada pelo IPEA, com os beneficiários do PMCMV foi constatada a ausência de trabalho social na maioria dos empreendimentos focados (Brasil, 2014). Além disso, em casos mais específicos, como nos de municípios do Rio Grande do Norte (Olives, 2017) e de Minas 
Vinicius de Souza Moreira - Suely de Fátima Ramos Silveira - Fillipe Maciel Euclydes

Gerais (Moreira, 2016), foram apontados os desafios e as fragilidades para a implementação desta etapa do PMCMV, tais como não realização de todas os estágios previstos (pré e pós-obra); ausência dos moradores no planejamento das ações; e baixa participação/envolvimento dos beneficiários nas atividades.

Nos locais em que o trabalho social foi executado, mencionou-se o estabelecimento de parcerias como importante fator na operacionalização das atividades. Os principais colaboradores, em geral, eram: a Polícia Militar (em ações sobre segurança pública); o Sebrae (no que se refere a cursos de capacitação); concessionárias de serviços públicos (para programas e ações envolvendo saneamento básico, higiene pessoal, cuidados com o patrimônio e melhor uso da energia elétrica); e as secretarias municipais de saúde, educação, meio ambiente e cultura (cada uma contribuindo nas temáticas que Ihes competiam). Nesse sentido, a atuação em parceria é um traço importante também assinalado nas pesquisas sobre o PMCMV, tanto no eixo urbano (Cardoso, 2013; Olives, 2017) quanto no rural (Bolter et al., 2015; Silva \& Cotto, 2016), pois são capazes de fortalecer os laços entre os integrantes das redes e auxiliar na colaboração para a realização das atividades (Holden \& Lin, 2012).

Além disso, nota-se presente o aspecto "colaborativo" em diversas outras experiências locais, o que reflete as parcerias entre agentes governamentais e sociedade e, também, internas ao próprio Estado (Farah, 2001; Lotta, 2017; Silva, Jaccoud, \& Beghin, 2005). Este atributo tem sido marcante nas pesquisas devido à própria característica descentralizada das principais políticas públicas e dos programas sociais brasileiros, que são, em sua maioria, formulados em nível federal e implementados em nível municipal. As experiências em nível local, por sua vez, arquitetaram parcerias e colaborações para atingirem a execução exitosa dos projetos, fato observado tanto na implementação do PMCMV em Minas Gerais quanto nos relatos de pesquisas em outros Estados brasileiros.

\section{CONCLUSÕES: O QUE AS EXPERIÊN- CIAS NOS ENSINAM?}

Ao buscar evidências da relação entre implementação, contexto e redes, no âmbito do PMCMV em municípios de Minas Gerais, reforçam-se os seguintes achados: os gestores públicos e outros agentes governamentais operam em várias redes (Agranoff \& Mcguire, 1999), concomitantemente a outros atores de distintos setores sociais (Sobrinho \& Helal, 2017), demonstrando a permeabilidade das fronteiras do Estado (Marques, 2006); embora diversos atores estejam envolvidos direta e indiretamente na implementação, existem entre eles diferenças de poder, influência e predomínio de grupos de interesse (Marques, 1999; 2006), deixando à margem atores importantes, como aqueles que representam a sociedade civil (Schneider, 2005); os elementos da estrutura relacional (Lotta \& Pavez, 2010) e do contexto influenciam as ações (Sobrinho \& Helal, 2017) e a tomada de decisões (Brugha \& Varvasovsky, 2000); e as características da rede podem mudar dependendo do tipo de relação entre atores, o que reflete diferentes imperativos na implementação (Holden \& Lin, 2012). É importante pontuar que esses elementos, em maior ou menor grau, também foram observados nesta pesquisa, bem como em outros contextos de implementação do PMCMV e, também, 
em outros programas públicos, conforme já discutido.

Além disso, foram identificadas características que inibem a efetividade do processo de implementação do rograma Minha Casa, Minha Vida com base no conjunto de municípios estudados, quais sejam: os valores da administração pública local; aspectos da estrutura organizacional da burocracia municipal; e as pressões contextuais.

Sobre os valores locais, o que dificulta a execução é a baixa apropriação do programa pela burocracia local. Para a execução exitosa do PMCMV, a intervenção deve ser incorporada aos interesses da gestão municipal, pois o município pode estender sua participação para além do aspecto social, mesmo não sendo o executor direto da construção das casas. Em referência à estrutura organizacional, a principal barreira refere-se à inexistência de um órgão multidisciplinar na hierarquia para atuar como coordenador das atividades. A ausência deste ator enfraquece a atuação da burocracia local e diminui a possibilidade de articulação entre os inúmeros agentes envolvidos. $E$, quanto às pressões contextuais, o empecilho associa-se ao imperativo do mercado imobiliário, cujas pressões econômicas e mercadológicas inibem e enfraquecem as negociações e aumentam o poder de influência das empresas, principalmente em municípios menos desenvolvidos e de menor porte. Associadas a isso, ações mal planejadas eram tomadas, incorrendo em problemas futuros (relacionados à infraestrutura urbana nas regiões escolhidas para abrigar os conjuntos habitacionais).

De outro lado, elementos facilitadores auxi- liavam na execução do programa, tais como: existência de corpo técnico capacitado nas áreas requeridas para $o$ adequado provimento habitacional (engenharia, geografia, arquitetura e urbanismo, gestão pública e social); engajamento da burocracia nas atividades do programa, havendo o acampamento dos processos desde as fases iniciais até a finalização de todas atividades; e compreensão do processo de implementação, que, além de proporcionar melhor entendimento das tarefas e da forma como devem ser executadas, permite complementar as negociações e fortalecer o estabelecimento de parcerias.

A partir da fundamentação teórica, a análise do PMCMV baseada em evidências empíricas permitiu, considerando os elementos facilitadores e inibidores da implementação do programa, identificar oportunidades de aprendizagem. A primeira lição extraída foi: o governo local é um coprodutor do programa. Ficou clara a necessidade de mais envolvimento do governo municipal, principalmente quanto à negociação de melhores condições tanto para a construção dos conjuntos habitacionais quanto para condução das atividades que envolvem o cadastramento/seleção das famílias e o trabalho social.

Outro aprendizado refere-se ao estabelecimento de parcerias. O provimento habitacional requer a reunião de esforços e múltiplos atores, que precisam agir de modo coordenado e articulado, para que o processo incorpore os diversificados interesses envolvidos.

$\mathrm{E}$, adicionalmente, observou-se que os fatores contextutais importam e podem moldar a atuação dos implementadores. Por conse- 
quência, conhecê-los e criar mecanismos para lidar com eles pode fazer com que as intervenções públicas se apropriem destes elementos em favor da efetividade das ações.

Por fim, após a materialização dos resultados da pesquisa, espera-se contribuir com o campo da análise de políticas públicas e, em especial, para os estudos direcionados à área habitacional, ao demonstrar as relações entre os atores locais e seus efeitos na implementação, atributos até então pouco explorados em pesquisas da área. Em termos práticos, as lições extraídas da pesquisa empírica fornecem elementos para a reflexão de pesquisadores, profissionais, organizações não-governamentais, gestores públicos e público em geral sobre os rumos da intervenção e como as características do contexto podem afetar os processos de implementação dos programas sociais.

\section{REFERÊNCIAS}

Abiko, A. K. (1995). Introdução à gestão habitacional. São Paulo, SP: EPUSP.

Adam, S., \& Kriesi, H. (2007). The network approach. In P. A. Sabatier (Ed.), Theories of the Policy Process (pp. 129-154). Cambridge, MA: Westview Press.

Agranoff, R., \& MCguire, M. (1999). Managing in network settings. Review of Policy Studies, 16(1), 18-41. doi:10.1111/j.1541-1338.1999. tb00839.x.

Amore, C. S., Shimbo, L. Z., \& Rufino, M. B. C. (Orgs.) (2015). Minha casa... e a cidade? Avaliação do Programa Minha Casa, Minha Vida em seis estados brasileiros. Rio de Ja- neiro, RJ: Letra Capital.

Andrade, A. R.. Silveira, S. F. R., Moreira, V. S., \& Rodrigues, L. P. D. (2017). Programa Nacional de Habitação Rural: Estudo à luz das Inadequações Habitacionais e das Intervenções Governamentais. In M. L. Emmendoerfer (Ed), Organizações Públicas, Inovações e Políticas de Desenvolvimento, (pp. 180-199). Viçosa, MG: IPPDS/UFV.

Bardach, E. (2001). Los Ocho Pasos para el Análisis de Políticas Públicas - Un manual para la prática. Centro de Documentación y Docencia Económicas. México.

Bardin, L. (2009). Análise de Conteúdo. Lisboa, Portugal: Edições 70.

Bekkers, V., Fenger, M., \& Scholten, P. (2017). Public policy in action: Perspectives on the policy process. Cheltenham, UK: Edward Elgar Publishing.

Bolter, J. A. G., Schneider, S., \& Haas, J. M. (2015). O Programa Nacional de Habitação Rural como estratégia de inclusão e desenvolvimento rural. In C. Grisa \& S. Schneider. (Eds.), Políticas públicas de desenvolvimento rural no Brasil (pp. 465-482). Porto Alegre, RS: Editora UFRGS.

Borgatti, S. P., \& Foster, P. C. (2003). The network paradigm in organizational research: A review and typology. Journal of Management, 29(6), 991-1013. doi:10.1016/S01492063(03)00087-4.

Börzel, T. A. (1998). Organizing Babylon - on the different conceptiopns of policy networks. Public Administration, 76(2), 253-273. doi:10.1111/1467-9299.00100. 
Brasil. (2018). Sistema Eletrônico do Serviço de Informação ao Cidadão. Requisição ao Ministério das Cidades. Recuperado de http://www.acessoainformacao.gov. $\mathrm{br} /$ ?came_from=http\%3A//www.acessoainformacao.gov.br/acessoainformacaogov

Brasil. Ministério das Cidades/Secretaria de Assuntos Estratégicos da Presidência da República. (2014). Pesquisa de satisfação dos beneficiários do Programa Minha Casa Minha Vida. Recuperado de http://repositorio.ipea.gov.br/bitstream/11058/3298/1/Pesquisa $\% 20$ de $\% 20$ satisfa\%C3\%A7\%C3\%A30\%20dos $\% 20$ benefici\%C3\%A1rios\%20do\%20Programa\%20Minha\%20Casa\%20Minha\%20 Vida.pdf

Brugha, R., \& Varvasovsky, Z. (2000). Stakeholder analysis: A review. Health Policy and Planning, 15(3), 239-246.

Cândido, G. G., \& Abreu, A. F. (2000, setembro). Os conceitos de redes e as relações interorganizacionais: um estudo exploratório. Artigo apresentado no Vigésimo Quarto Encontro da ANPAD, Rio de Janeiro, RJ.

Capella, A. C. N., \& Brasil, F. G. (2015). Análise de Políticas Públicas: Uma Revisão da Literatura sobre o Papel dos Subsistemas, Comunidades e Redes. Novos Estudos. CEBRAP, 101, 57-76. doi:10.1590/S010133002015000100003.

Cardoso, A. L. (2013). O programa Minha Casa, Minha Vida e seus efeitos territoriais. Recuperado de http://observatoriodasmetropoles.net.br/wp/segregacao-residencial-e-politica-habitacional-no-brasil/
Farah, M. F. S. (2001). Parcerias, novos arranjos institucionais e políticas públicas no nível local de governo. Revista de Administração Pública, 35(1), 119-144.

Ferrari, R. M., \& Nunes. L. V. (2008). Policy Networks: Uma Teoria de Políticas Públicas? Artigo apresentado no terceiro Encontro de Administração Pública e Governança, Salvador, BA.

Fontes, B. A. S. M., Leal, S. M. R,. \& Melo, N. M. L. (1995). Gestión local en el Nordeste de Brasil: En busca de nuevos paradigmas. Revista Mexicana de Sociología, 57(2), 123142.

Frey, K. (2000). Políticas públicas: Um debate conceitual e reflexões referentes à prática da análise de políticas públicas no Brasil. Planejamento e Políticas Públicas, 21, 211259.

Fundação João Pinheiro. Centro de Estatísticas e Informações. (2016). Déficit habitacional no Brasil 2013-2014. Recuperado de http://www.fjp.mg.gov.br/index.php/docman/ cei/informativos-cei-eventuais/634-deficit-habitacional-06-09-2016/file

Hill, M., \& Hupe, P. (2009). Implementing public policy: An introduction to the study of operational governance. London, UK: Sage Publications.

Holden, C. A., \& Lin, V. (2012). Network structures and their relevance to the policy cycle: a case study of The National Male Health Policy of Australia. Social Science \& Medicine, 74(2), 228-235. doi:10.1016/j.socscimed.2011.10.015 
Howlett, M., \& Maragna, A. (2006). How big is a policy network? An assessment utilizing data from Canadian royal commissions 1970-2000. Review of Policy Reserach, 23(2), 433-452.

Jann, W., \& Wegrich, K. (2007). The theories of the policy cycle. In F. Fisher, G. J. Miller, \& M. S. Sidney (Eds.), Handbook of policy analysis: Theory, and method (pp. 43-62). New York, NY: CRC Press.

Lima, J. J. F., Ponte, J. P. X., Rodrigues, R. M., Neto, R. V., \& Melo, A. C. C. (2013). A promoção habitacional através do Programa Minha Casa Minha Vida na Região Metropolitana de Belém. In A. L. Cardoso (Org.). O programa Minha Casa, Minha Vida e seus efeitos territoriais (pp.161-185). Rio de Janeiro, RJ: Letra Capital.

Lima, L. L., \& D'ascenzi, L. (2013). Implementação de políticas públicas: Perspectivas analíticas. Revista de Sociologia Política, 21(48), 101-110. doi:10.1590/S010444782013000400006

Lotta, G. S. (2017). Redes e parcerias em políticas sociais: Novos arranjos institucionais de coprodução de serviços nos munic ípios brasileiros. Brasília, DF: Enap. Recuperado de http://repositorio.enap.gov.br/ bitstream/1/2884/1/Cadernos_51_Redes_ parcerias_miolo_digital.pdf

Lotta, G. S. L., \& Pavez, T. R. (2010). Agentes de implementação: Mediação, dinâmicas e estruturas relacionais. Cadernos Gestão Pública e Cidadania, 15(56), 109-125. doi:10.12660/cgpc.v15n56.3205
Magris, F. H. (2013). O Programa Minha Casa Minha Vida e a reconfiguração urbana do Município de Serra-ES (Dissertação de mestrado). Universidade Federal do Espírito Santo, Viória, ES, Brasil.

Marques, E. C. (1999). Redes sociais e instituições na construção do Estado e da sua permeabilidade. Revista Brasileira de Ciências Sociais, 14(41), 45-67. doi:10.1590/ S0102-69091999000300004

Marques, E. C. (2000). Estado e redes sociais: Permeabilidade e coesão nas políticas urbanas no Rio de Janeiro. São Paulo, SP: Editora Revan.

Marques, E. C. (2006). Redes Sociais e Poder no Estado Brasileiro: Aprendizados a Partir das Políticas Urbanas. Revista Brasileira de Ciências Sociais, 21(60), 15-41. doi:10.1590/ S0102-69092006000100002

Mendonza, E. C. (2007). Usos y costumbres em la hechura de las políticas públicas en México. Límites de las policy sciences en contextos cultural y políticamente diferentes. In Jefatura de Gabinete de Ministros. (Org.), Lecturas sobre el Estado y las políticas públicas: Retomando el debate de ayer para fortalecer el actual. Buenos Aires, Argentina.

Moreira, V. S. (2016). Avaliação dos resultados do programa "Minha casa, minha vida" em Minas Gerais (Dissertação de Mestrado). Universidade Federal de Viçosa, Viçosa, MG, Brasil.

Moreira, V. S., \& Silveira, S. F. R. (2017). Estariam satisfeitos os beneficiários do Programa Minha Casa, Minha Vida? Evidências empíricas em municípios do estado de Minas 
Gerais. Revista Eletrônica de Ciência Administrativa, 16(2), 106-126. doi:10.21529/ RECADM.2017008

Moysés, A., Cunha, D. F., Borges, E. M., \& Maia, T. C. B. (2013). Impactos da produção habitacional contemporânea na Região Metropolitana de Goiânia: Dinâmica, estratégias de mercado e a configuração de novas espacialidades e centralidades. In A. L. Cardoso (Ed.). O programa Minha Casa, Minha Vida e seus efeitos territoriais (pp. 255-278). Rio de Janeiro, RJ: Letra Capital.

Nascimento, E. A. (2017). O Programa Minha Casa Minha Vida no Rio Grande do Norte: Uma análise comparativa da habitação popular em contextos urbanos distintos (Tese de doutorado). Universidade Federal do Rio Grande do Norte, Natal, RN, Brasil.

Nelson, R. (1984). O uso da Análise de Redes Sociais no estudo das estruturas organizacionais. Revista de Administração de Empresas, 24(4), 150-157. doi:10.1590/ S0034-75901984000400025

Olives, S. J. C. (2017). Desafios e fragilidades do trabalho social no Programa Minha Casa Minha Vida na região metropolitana de Natal (Dissertação de mestrado). Universidade Federal do Rio Grande do Norte, Natal, RN, Brasil.

Pressman, J. L., \& Wildavsky, A. (1973). Implementation. Berkeley, CA: University of California Press.

Rhodes, R. (1997). Understanding Governance: Policy Networks, Governance, Reflexivity and Accountability. Buckingham y Philadelphia: Open University Press.
Rolnik, R., Pereira, A. L. dos S., Moreira, F. A., Royer, L. de O., lacovini, R. F. G., \& Nisida, V. C. (2015). O Programa Minha Casa Minha Vida nas regiões metropolitanas de São Paulo e Campinas: Aspectos socioespaciais e segregação. Cadernos Metrópole, 17(33), 127-154. doi:10.1590/2236-9996.2015-3306

Sabatier, P. A. (2007). Theories of the Policy Process. Boulder, CO: Westview Press.

Schneider, V. (2005). Redes de políticas públicas e a condução de sociedades complexas. Civitas, 5(1), 29-58. doi:10.15448/19847289.2005.1.33

Secchi, L. (2013). Políticas Públicas - Conceitos, esquemas de análise, casos práticos. São Paulo, SP: Cengage Learning.

Silva, A. A. (2014). Um sonho distante: Reflexões sobre acessibilidade nos conjuntos habitacionais do PMCMV faixa 1 na região metropolitana de Natal (Dissertação de Mestrado). Universidade Federal do Rio Grande do Norte, Natal, RN, Brasil.

Silva, F. B., Jaccoud, L., \& Beghin, N. (2005). Políticas Sociais no Brasil: Participação Social, Conselhos e Parcerias. In L. Jaccoud (Ed.). Questão Social e Políticas Sociais no Brasil Contemporâneo. Brasília, DF: IPEA.

Silva, P. L. B., \& Melo, M. A. B. (2000). O processo de implementação de políticas públicas no Brasil: características e determinantes da avaliação de programas e projetos. UNICAMPI/NEPP.

Silva, S. M. M. M. (2018). Gestão social e organização comunitária no Programa Mi- 
nha Casa, Minha Vida: O caso no Residencial Ruy Pereira dos Santos (Dissertação de Mestrado). Universidade Federal do Rio Grande do Norte, Natal, RN, Brasil.

Silva, S. S., \& Coto, G.C. (2015). Redes públicas de cooperação e o desenvolvimento Local: A experiência do Programa Nacional de Habitação Rural (PNHR) no Alto Vale do Itajaí. Revista de Ciências da Administração, 17, Edição Especial, 165-182.

Silveira, S. F. R., Moreira, V. S., Silva, F. C. \& Andrade, J. H. (2018). Social Participation in The Program "Minha Casa, Minha Vida": Analysis of Municipal Housing Councils. Praxis Sociológica, 23,101-121.

Soares, I. O., Carvalho, A. W. B., Ribeiro FiIho, G. B. \& Pinto, N. M. A. (2013). Interesses especulativos, atuação do Estado e direito à cidade: $\mathrm{O}$ caso do programa "Minha Casa Minha Vida" em Uberaba (MG). Revista Brasileira de Gestão Urbana, 5(1), 119-131. doi:10.7213/urbe.7789

Sobrinho, J. M., \& Helal, D. H. (2017). A Implementação de Políticas Públicas voltadas a atividades artesanais: Análise do Programa de Artesanato da Paraíba. Organizações \& Sociedade, 24(80), 115-134. doi:10.1590/1984-9230806

Sovacool, B. K., Linnér, B. O. \& Klein, R. J. T. (2017). Climate change adaptation and the Least Developed Countries Fund (LDCF): Qualitative insights from policy implementation in the Asia-Pacific, Climatic Change, 140(2), 209-226. doi:10.1007/s10584-016$1839-2$
Steiner, P. (2006). A Sociologia Econômica. São Paulo, SP: Atlas.

Thery, H. (2017). Novas Paisagens Urbanas do Programa Minha Casa, Minha Vida. Mercator, 16, 1-14. doi:4215/rm2017.e16002

Tichy, N., Tushman, M., \& Fombrun, C. (1979). Social Network Analysis for Organizations. Academy of Management Review, 4(4), 507519. doi:10.5465/amr.1979.4498309

Vasconcellos, C. P. (2015). As políticas públicas de habitação e o território: análise do Programa Minha Casa, Minha Vida nos municípios de Carazinho, Marau e Passo Fundo/RS. (Tese de doutorado). Universidade Federal do Rio Grande do Sul, Porto Alegre, RS, Brasil.

Viana, A. L. (1996). Abordagens Metodológicas em Políticas Públicas. Revista de Administração Pública, 30(2), 5-43.

Vicentim, T. N., \& Kanashiro, M. (2016). Análise do comércio e dos serviços nos empreendimentos do Programa Minha Casa, Minha Vida (PMCMV): estudo de caso do Residencial Vista Bela - Londrina, PR. Ambiente Construído, 16(4), 227-250. doi:10.1590/ s1678-86212016000400116.

Wasserman, S., \& Faust, K. (2009). Social Network Analysis: Methods and Applications. New York, NY: Cambridge Press.

Ysa, T., Sierra, V., \& Esteve, M. (2014). Determinants of network outcomes: The impact of management strategies. Public Administration, 92(3), 636-655. doi:10.1111/padm.12076 